\title{
Constant-load exercise decreases the serum concentration of myeloperoxidase in healthy smokers and smokers with COPD
}

This article was published in the following Dove Press journal:

International Journal of COPD

21 July 2015

Number of times this article has been viewed

\section{Olaf Holz',* \\ Stefan Roepcke ${ }^{2, *}$ \\ Henrik Watz ${ }^{3}$ \\ Uwe Tegtbur ${ }^{4}$ \\ Gezim Lahu ${ }^{2}$ \\ Jens M Hohlfeld'}

'Fraunhofer Institute for Toxicology and Experimental Medicine (ITEM), German Center for Lung Research (DZL, BREATH), Hannover, Germany; ${ }^{2}$ Takeda Pharmaceuticals International $\mathrm{GmbH}$, GlattparkOpfikon, Switzerland; ${ }^{3}$ Pulmonary Research Institute at Lung Clinic Grosshansdorf, German Center for Lung Research (DZL, ARCN), Grosshansdorf, ${ }^{4}$ Institute for Sports Medicine, Hannover Medical School (MHH), Hannover, Germany

*These authors contributed equally to this work
Correspondence: Olaf Holz

Department of Clinical Airway Research, Fraunhofer Institute for Toxicology and Experimental Medicine, Clinical Research Center (CRC), 30625 Hannover,

Germany

$\mathrm{Tel}+495$ II 53508 I4I

Fax +49 5II 53508104

Email olaf.holz@item.fraunhofer.de

\begin{abstract}
There is an ongoing demand for easily accessible biomarkers related to pathophysiological processes in chronic obstructive pulmonary disease (COPD). Short-term intense exercise is known to increase the peripheral blood levels of cytokines. Therefore, we tested the potential and the repeatability of an exercise challenge to amplify seven serum biomarkers (interleukin 6 [IL6], C-reactive protein [CRP], myeloperoxidase [MPO], leukotriene B4, soluble intercellular adhesion molecule 1 , soluble vascular cell adhesion molecule 1 , and von Willebrand factor [VWF]) in smokers with and without COPD. Twenty-three smokers with moderate COPD (GOLD 2) and 23 sex- and age-matched healthy smokers underwent up to 30 -minute submaximal, constant-load exercise ( $75 \%$ of maximum work load) on two occasions separated by 4 weeks (second challenge $n=19 / 20$ ). Serum samples were obtained before, 5 minutes after the start, at the end of exercise (maximum 30 minutes or until exhaustion), and after additional 20 minutes of rest. The median (interquartile range) exercise time until exhaustion in the two challenges was 10.0 (4.0) minutes and 10.0 (8.0) minutes in smokers with COPD and 22.0 (16.0) minutes and 26.5 (14.5) minutes in healthy smokers. The exercise challenge significantly increased the serum concentrations of IL6 and VWF, but decreased the concentrations of MPO. Healthy smokers showed a significantly greater increase (at the end of exercise compared to before exercise $)$ in IL6 $(P=0.01)$ and a larger decline $(P=0.03)$ in MPO. The overall profile of the serum markers during the exercise challenge was shown to be repeatable in the second challenge. In summary, intense load exercise is capable of changing the concentration of inflammatory and endothelial function markers. Especially, the decline in the level of MPO, a marker closely related to cardiovascular risk, appears to be of clinical interest, as the exercise-induced decline might be related to the beneficial effects of physical activity in general.
\end{abstract}

Keywords: serum biomarker, systemic inflammation, physical activity

\section{Introduction}

For therapeutic and diagnostic reasons, but also in clinical and pharmacological research, there is a high demand for easily accessible biomarkers that reflect the complex nature of physiological and pathophysiological changes in chronic obstructive pulmonary disease (COPD).

Systemic inflammation is thought to play an important role in the pathogenesis of COPD. ${ }^{1-3}$ Among others, peripheral blood levels of fibrinogen, adiponectin, interleukin 6 (IL6), and C-reactive protein (CRP) were shown to be increased ${ }^{2,4,5}$ and to be related to exercise tolerance, ${ }^{6,7}$ exacerbation rate, ${ }^{8}$ and mortality. ${ }^{1}$ However, the differences between the mean absolute resting levels in IL6 and CRP between COPD patients and 
healthy smokers are small, and there is considerable variation in the level of inflammatory markers within groups. ${ }^{1}$

Breathlessness and reduced exercise capacity are well-known symptoms of COPD. They are accompanied by bronchoconstriction, lung hyperinflation, mismatch of ventilation and perfusion, pulmonary vascular disease, skeletal muscle atrophy, muscle fiber shift, and gas-exchange abnormalities. ${ }^{9-11}$ Moreover, breathlessness and early tiring (fatigue) leads to less physical activity, which also worsens the disease, as physical inactivity itself is related to systemic inflammation in COPD. ${ }^{7,12}$ Quadriceps muscle weakness and increased fatigability are well known in COPD, and the fatigability of the distal leg muscles is also higher in patients with COPD. ${ }^{13}$ It is known from healthy sedentary subjects that they respond with increased levels of plasma IL6, tumor necrosis factor alpha ( $\mathrm{TNF} \alpha)$, and markers for oxidative stress during and following maximal cycling exercise. ${ }^{14}$ The extent of increase depends on the intensity and duration of exercise. ${ }^{15}$ In 2008, Jammes et al $^{16}$ compared the expression of oxidant and inflammatory responses to maximal cycling exercise in COPD patients and healthy controls to test the effect of hypoxemia on muscle metabolism in COPD patients. They showed that an increase in IL6 and TNF $\alpha$ occurred earlier and that the absolute change in these cytokine levels was more pronounced in COPD patients.

Therefore, the basic idea for using exercise challenge as a model was primarily based on the hypothesis that challenged patients could potentially amplify biomarkers related to specific pathophysiological processes in COPD. For our study, we recruited smokers with moderate COPD (GOLD 2) and sex- and age-matched healthy smokers as controls. We analyzed IL6 and CRP, which are known to be related to health status, exercise tolerance, and exacerbations of COPD patients, ${ }^{6,8}$ as well as soluble vascular cell adhesion molecule 1 (sVCAM1), soluble intercellular adhesion molecule 1 (sICAM1), and von Willebrand factor (VWF) as markers of endothelial function. In addition, we assessed myeloperoxidase (MPO) as an inflammatory marker, which has been associated with lung function, ${ }^{17}$ but which is also considered as a biomarker for cardiovascular disease risk stratification, ${ }^{18}$ and leukotriene (LT) B4 as a marker involved in inflammatory processes inducing the adhesion and activation of leukocytes to endothelial cells. To determine the repeatability of the findings, the exercise challenge was performed on two occasions. This study was part of a comprehensive exploratory biomarker study in serum, bronchoalveolar lavage, bronchial biopsies, and induced sputum of smokers with moderate COPD (GOLD 2). ${ }^{19}$

\section{Material and methods Subjects}

Twenty-three subjects with moderate COPD (GOLD 2$)^{9}$ and 23 age- and sex-matched healthy controls were enrolled in this prospective exploratory biomarker study (Table 1). Six subjects in each study group were women. All were current smokers with a smoking history of at least 10 pack-years and free of exacerbations or acute infections within 4 weeks prior to the study days. Among other inclusion criteria, a body mass index (BMI) $>18$ and $\leq 30 \mathrm{~kg} / \mathrm{m}^{2}$ and a postbronchodilator increase in forced expiratory volume in 1 second $\left(\mathrm{FEV}_{1}\right) \leq 15 \%$ were required. Subjects or patients with any evidence for a disease that would affect the safety during exercise challenge, including a history of pneumonia within the last 6 months or of asthma, were excluded. The study was conducted in accordance with Good Clinical Practice and the Declaration of Helsinki. Subjects gave their written informed consent. The study was approved by the Ethical Committee of Hannover Medical School.

\section{Study design}

During screening (maximum 3 weeks prior to visit 1), the subject's demographics and medical history were obtained (Figure 1). Blood was drawn for basic hematology and biochemistry. Lung function and electrocardiogram (ECG) were

Table I Demographic and physiological parameters

\begin{tabular}{|c|c|c|}
\hline & $\begin{array}{l}\text { Healthy } \\
\text { smokers }(n=23)\end{array}$ & $\begin{array}{l}\text { COPD } \\
\text { smokers }(n=23)\end{array}$ \\
\hline Men/women & $6 / 17$ & $6 / 17$ \\
\hline Age (years) & $54(42,65)$ & $55(46,68)$ \\
\hline Weight (kg) & $79.6 \pm 14.0$ & $77.3 \pm 12.3$ \\
\hline $\mathrm{BMI}\left(\mathrm{kg} / \mathrm{m}^{2}\right)$ & $25.4 \pm 2.5$ & $25.2 \pm 3.4$ \\
\hline Pack-years & $39 \pm 23.2$ & $47.9 \pm 11.0 * * *$ \\
\hline Cigarette per day & $20.7 \pm 8.9$ & $24.8 \pm 6.2 * * *$ \\
\hline Cotinine $(\mathrm{ng} / \mathrm{mL}): \mathrm{Scr}$ & $\mathrm{I}, 262 \pm 722$ & I,566士989 \\
\hline VI & I,378 \pm 722 & $\mathrm{I}, 772 \pm \mathrm{I}, \mathrm{I} 07$ \\
\hline V3 & $I, 45 I \pm 823$ & $\mathrm{I}, 779 \pm 1,0 \mathrm{I}$ \\
\hline $\mathrm{FEV}_{1}(\mathrm{~L})^{\mathrm{a}}$ & $3.8 \pm 0.8$ & $2.2 \pm 0.4 * * *$ \\
\hline $\mathrm{FEV}_{1} \%$ predicted $^{\mathrm{a}}$ & I $12.5 \pm \mid 4.1$ & $66.1 \pm 7.2^{* * *}$ \\
\hline $\mathrm{FEV}_{\mathrm{l}} / \mathrm{FVC}(\%)^{\mathrm{a}}$ & $75.4 \pm 5.0$ & $50.0 \pm 8.7 * * *$ \\
\hline$W_{\text {peak }}(W)$ & $|54.8 \pm 35|$. & $110.9 \pm 23.9 * * *$ \\
\hline $\mathrm{PaO}_{2}$ & $82.9 \pm 9.7$ & $73.5 \pm 5.4$ \\
\hline $\mathrm{PaCO}_{2}$ & $41.6 \pm 2.0$ & $41.3 \pm 2.5$ \\
\hline
\end{tabular}

Notes: Values are presented as mean $\pm S D$, except for age where we report median (Min, Max); $* P<0.05, * * P<0.01, * * * P<0.001$. $W_{\text {peak }}$ means peak exercise level that could be maintained for 30 seconds (during an escalation scheme with a stepwise increase in the work rate by $10 \mathrm{~W}$ every minute. ${ }^{a}$ Data of COPD patients was assessed post bronchodilator treatment. $\mathrm{PaO}_{2}, \mathrm{PaCO}_{2}$ stand for partial pressure of $\mathrm{O}_{2}$ and $\mathrm{CO}_{2}$ derived from the blood gas analysis.

Abbreviations: COPD, chronic obstructive pulmonary disease; BMI, body mass index; Scr, screening; $V$, visit; SD, standard deviation; Min, minimum; Max, maximum; $\mathrm{FEV}_{1}$, forced expiratory volume in I second; FVC, forced vital capacity. 
Exercise capacity

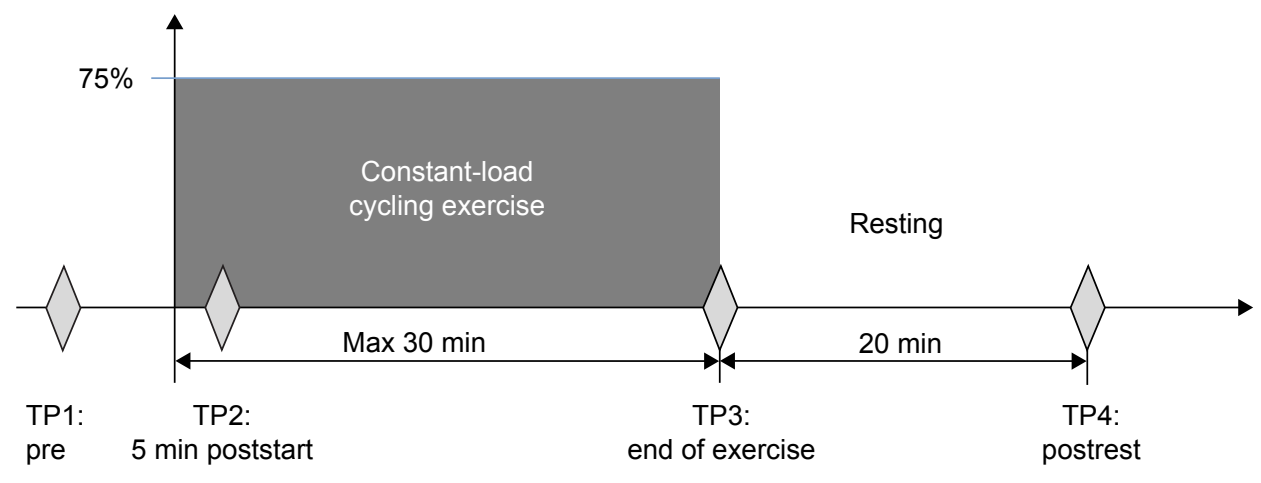

Serum samples

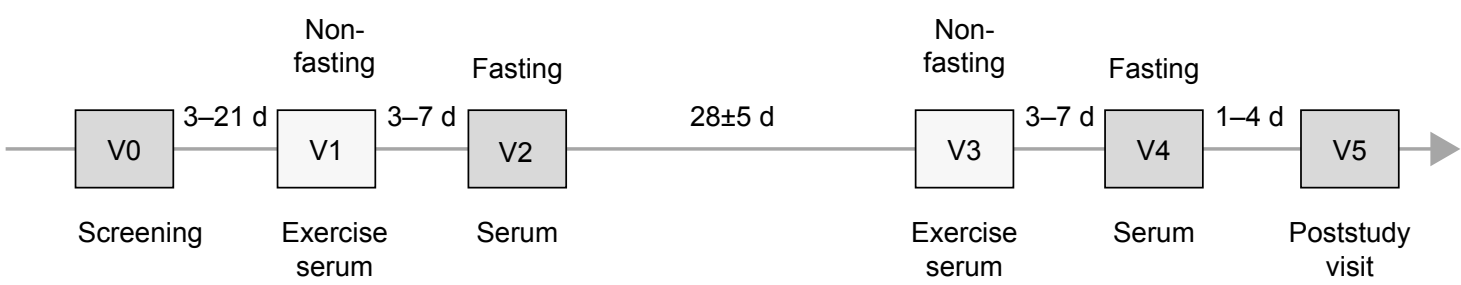

Figure I Study design.

Notes: The TPI and TP2 were fixed, while constant-load exercise was performed until the subject was exhausted; TP3 was therefore different between individuals (maximum 30 minutes). The period of rest was always 20 minutes following the end of exercise.

Abbreviations: TP, time points; Max, maximum; min, minutes; $V$, visit; d, day.

assessed, and urine was tested for cotinine. Subjects then returned for a total of five visits. Visits 1 and 2 (separated by $3-7$ days) were followed $28 \pm 5$ days later by visits 3 and 4 (separated by 3-7 days). The exercise tests were performed under nonfasting conditions during visits 1 and 3 following a standardized breakfast. Subjects were discharged from the study in visit 5 ( $1-4$ days after visit 4 ). Five of the 46 subjects did not take part in the second exercise test during visit 3 .

\section{Cycling exercise}

At the screening visit, the peak work capacity $\left(W_{\text {peak }}\right)$ was determined by an escalation scheme with a stepwise increase in the work rate by $10 \mathrm{~W}$ every minute and by keeping the pedaling rates at $50-70 \mathrm{rpm} .{ }^{20} W_{\text {peak }}$ was defined as the highest work rate that could be maintained for at least 30 seconds. For the constant-load exercise, after a short warm-up period, the work rate was increased to $75 \%$ of $W_{\text {peak }}$ (Figure 2). The subjects were encouraged to exercise for 30 minutes, but they were allowed to stop the exercise before this, if needed. Blood oxygenation $\left(\mathrm{SpO}_{2}\right)$ was monitored during exercise by pulse oximetry.

Venous blood sampling was carried out at four time points: before exercise, after 5 minutes of loaded exercise, end of loaded exercise (maximum 30 minutes), and 20 minutes after exercise (Figure 1). Serum was aliquoted and kept frozen at $-80^{\circ} \mathrm{C}$ until analysis.

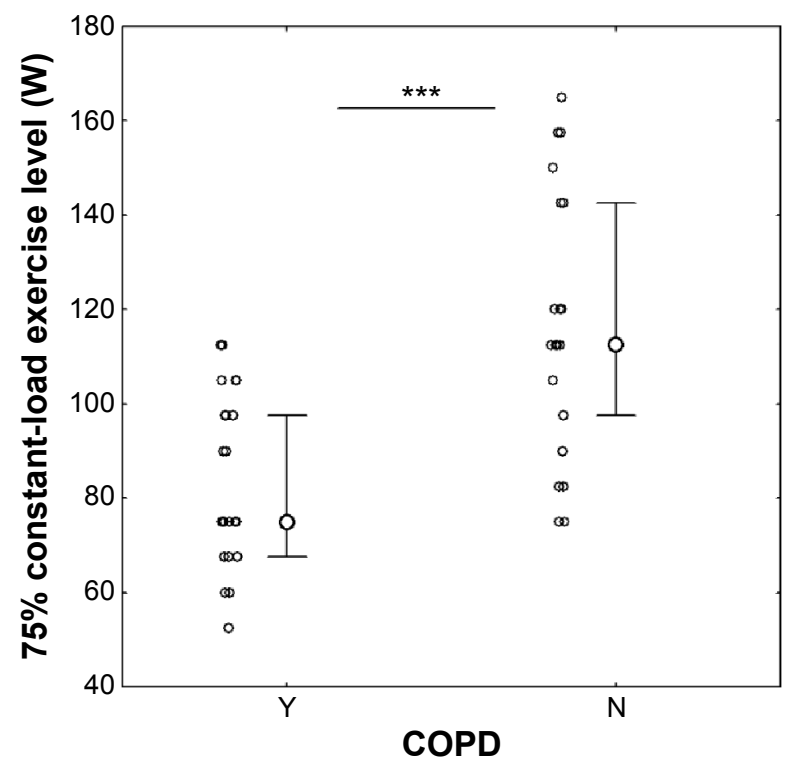

Figure 2 Individual constant-load exercise level for COPD smokers ( $\mathrm{Y}$ ) and for healthy smokers $(\mathrm{N})$.

Notes: Median levels and interquartile ranges are presented. $* * * P<0.001$.

Abbreviation: COPD, chronic obstructive pulmonary disease. 


\section{Analysis}

IL6, LTB4, and VWF were analyzed in the exercise serum samples by enzyme-linked immunosorbent assay (ELISA). MPO, CRP, sICAM1, and sVCAM1 were analyzed by a Luminex instrument. Lactate was measured as part of a metabolite panel using electrospray ionization tandem mass spectrometry at Biocrates Life Science AG, Austria, according to their standard operating procedure. ${ }^{21}$ The experimental procedure is described in detail by the patent US 2007/0004044 (accessible at http://www.freepatentsonline.com/20070004044.html). ${ }^{22}$

\section{Statistical analysis}

Data are displayed as arithmetic mean and standard deviation (SD) or median and interquartile ranges (IQRs). Prior to statistical analysis, we corrected the original measurements for plate effects and averaged the duplicated measurements. Data were log-transformed if not normally distributed. Interrelationships between parameters were investigated by computing the Pearson correlation coefficient. Analysis of variance (ANOVA) was conducted based on a repeated measurement model to assess changes in biomarker levels during exercise challenge. For comparisons between two groups, the Mann-Whitney $U$-test statistic was calculated. The Newman-Keuls test statistic was used for post hoc analysis. Differences between groups were reported if the $P$-values of the parametric as well as of an additional nonparametric analysis were $<0.05$. It should be noted that, due to the exploratory nature of this study and because of the simultaneous investigation of many analytes (no adjustment of the significance level has been applied), the familywise error rate is not controlled. Hence, the $P$-values are utilized as standardized measures for the extent of the difference between the two study groups. Intraclass correlation coefficients (ICCs) were derived from one-way ANOVA tables as the ratio of variance among subjects to total variance based on the repeated measurements. ${ }^{23}$ (BMS - WMS/2)/([BMS - WMS/2]+WMS), where BMS means between-group mean square and WMS means within-group mean square. For the statistical analysis, we used the software Statistica (Statsoft, Germany).

\section{Results \\ Demographics}

Subjects of the COPD and the control group were matched with respect to sex, age, and smoking behavior. Urine cotinine measurements showed no significant differences between groups, despite the COPD patients reporting slightly higher daily cigarette consumption. COPD patients had lower lung function values, oxygen saturation, and a lower peak exercise capacity at screening (Table 1).

\section{Duration of exercise}

The median (IQR) exercise time until exhaustion was 10.0 (4.0) minutes and 10.0 (8.0) minutes in COPD and 22.0 (16.0) minutes and 26.5 (14.5) minutes in healthy smokers (Figure 3 ). These median time periods are displayed on the $x$-axis in Figures $4-6$. The $\mathrm{SpO}_{2}$ (pulse oximetry) value was recorded at all blood sampling time points and it never

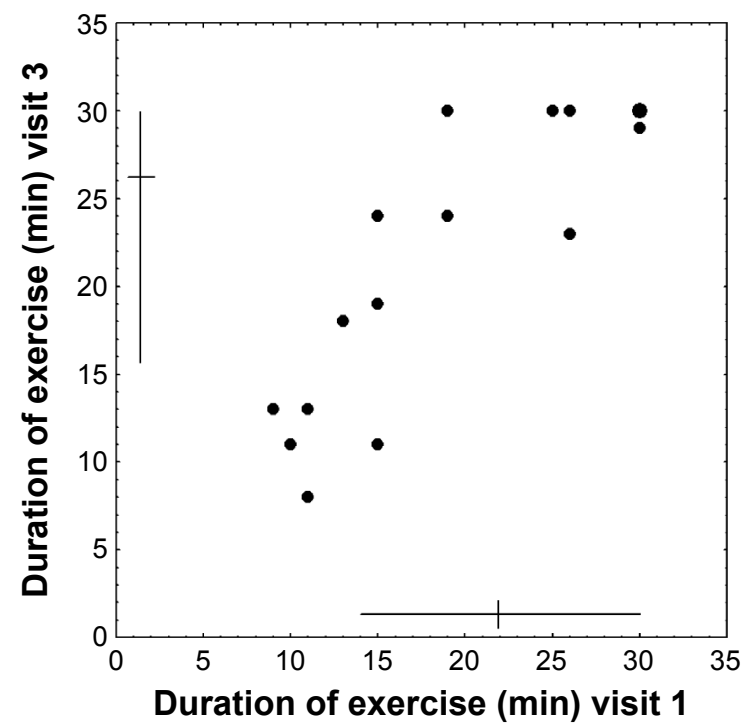

Figure 3 Individual time points until the exercise challenge was terminated due to exhaustion.

Notes: (Left) COPD smokers. (Right) Healthy smokers. Both axes display the absolute duration of exercise. The enlarged open dot (COPD smoker) represents two data points, and the enlarged closed dot (healthy smoker) represents six data points. Median and interquartile ranges are displayed.

Abbreviations: COPD, chronic obstructive pulmonary disease; min, minutes. 

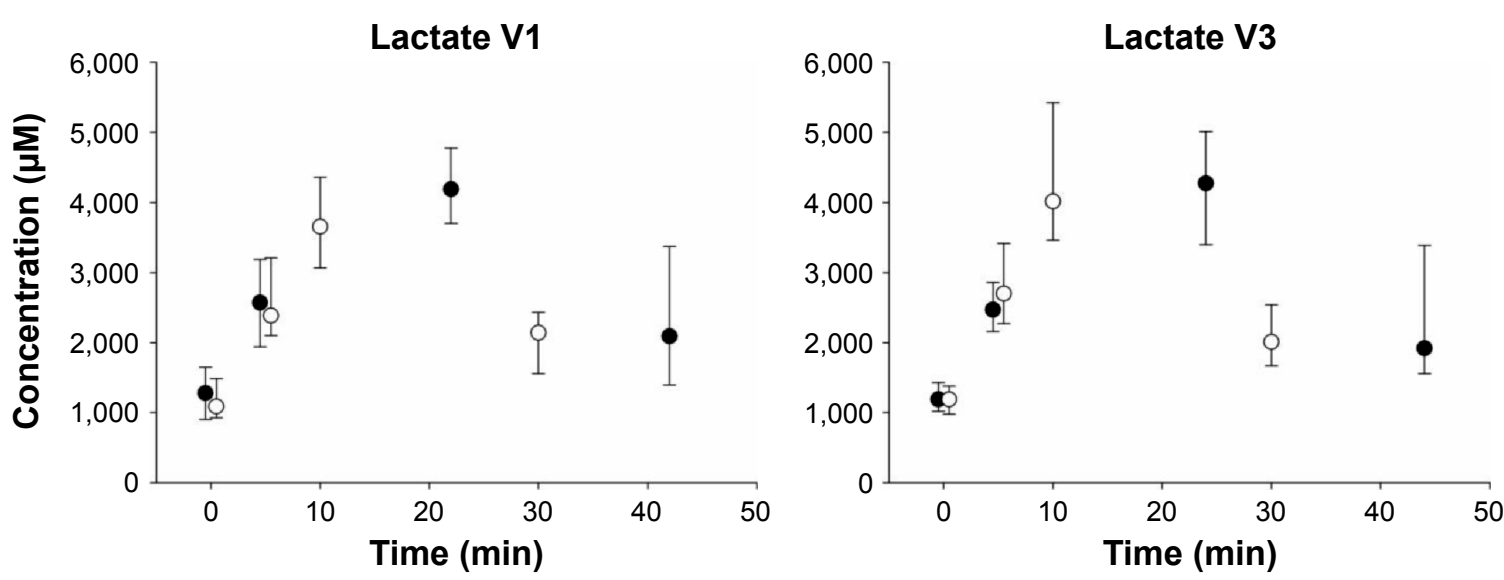

Figure 4 Time course for the peripheral blood concentrations of lactate, separately for COPD smokers (open symbols) and healthy smokers (closed symbols).

Notes: The results of visit I are displayed on the left $(n=23 / 23)$; the results of the repeated visit ( $28 \pm 5$ days later, $n=20 / 19)$ are displayed on the right. Blood was drawn before (displayed at 0 minutes), after 5 minutes of exercise (displayed at 5 minutes), at the time of exhaustion or a maximum duration of 30 minutes exercise, and following a period of 20 minutes of rest (both displayed at the median duration for each group). Median levels and interquartile ranges are presented. There were no differences between COPD smokers and healthy smokers at the different time points.

Abbreviations: COPD, chronic obstructive pulmonary disease; min, minutes.

dropped below $94 \%$ in any subject during the study. The comparable lactate levels indicated that the metabolic burden was comparable between groups (Figure 4).

\section{Baseline concentrations prior to exercise}

At baseline following a standardized breakfast (visit 1: $\mathrm{n}=23$ COPD smokers/23 healthy smokers), COPD patients had higher serum concentrations of IL6 $(P<0.001)$, CRP $(P<0.005)$, sVCAM1 $(P<0.01)$, sICAM1 $(P<0.02)$, and VWF $(P<0.001)$ (Figures 5 and 6$)$. These differences were smaller at baseline of the second challenge, most likely due to the lower subject numbers $(n=21 / 19)$.

\section{Changes in concentrations during exercise}

The analysis of the whole dataset including all subjects and all measurements showed that the exercise challenge changed the concentrations of IL6 $(P<0.001)$, MPO $(P<0.001)$, sICAM1 $(P<0.05)$, VWF $(P<0.001)$, and LTB4 $(P<0.05$, repeated measures ANOVA including all four time points from both visits; diagnosis and visits as factors).

Compared to smokers with COPD, healthy smokers showed a greater percent increase (end of exercise relative to before exercise $)$ in serum IL6 $(P=0.01)$ and CRP $(P=0.05)$ and a larger decline $(P=0.03)$ in serum MPO at the end of the exercise period.

To consider the fact that the duration of exercise differed between groups, we also calculated the percent change of each marker per minute. Due to the much shorter duration until exhaustion, the percent change per minute was larger for COPD patients compared to healthy smokers for IL6 $(P=0.004), \mathrm{MPO}(P=0.0001)$, and $\mathrm{CRP}(P=0.06)$, but also for
sVCAM1 ( $P=0.003)$, sICAM1 $(P=0.0001), \operatorname{VWF}(P=0.009)$, and LTB4 $(P=0.0001)$.

We observed a correlation between serum concentrations of IL6 and CRP before, during, and at the end of exercise (log-transformed data of all subjects, $r=0.56,0.61,0.54$, at least $P<0.003$ ). Correlations with $r>0.5$ were also observed for $\mathrm{SVCAM}$ and SICAM.

\section{Changes in concentrations during recovery}

In healthy smokers, the change in IL6 serum concentrations during the recovery phase $(\%$, level at end of 20 minutes recovery relative to end of exercise) was different from those of COPD smokers $(P=0.01)$ because only in healthy smokers the IL6 levels continued to increase during the recovery phase. No such differences during the recovery phase were observed for the other markers.

\section{Reproducibility of the exercise challenge model}

In this study, the exercise challenge was repeated 4 weeks after the first challenge. Figures 5 and 6 show that the median levels of all markers show almost identical response patterns. On the individual level, we found a very good reproducibility for the duration until the end of exercise ( $\mathrm{ICC}=0.86$; correlation coefficient, $r=0.87$ ). The absolute serum concentration of IL6 at the end of exercise showed low repeatability $(0.21,0.21)$. Better values were found for the change in IL6 concentration relative to baseline $(0.53,0.54)$. A fairly good repeatability was also found for the absolute serum concentration of MPO $(0.72,0.72)$ and $\operatorname{VWF}(0.61,0.60)$ at the end of exercise. 

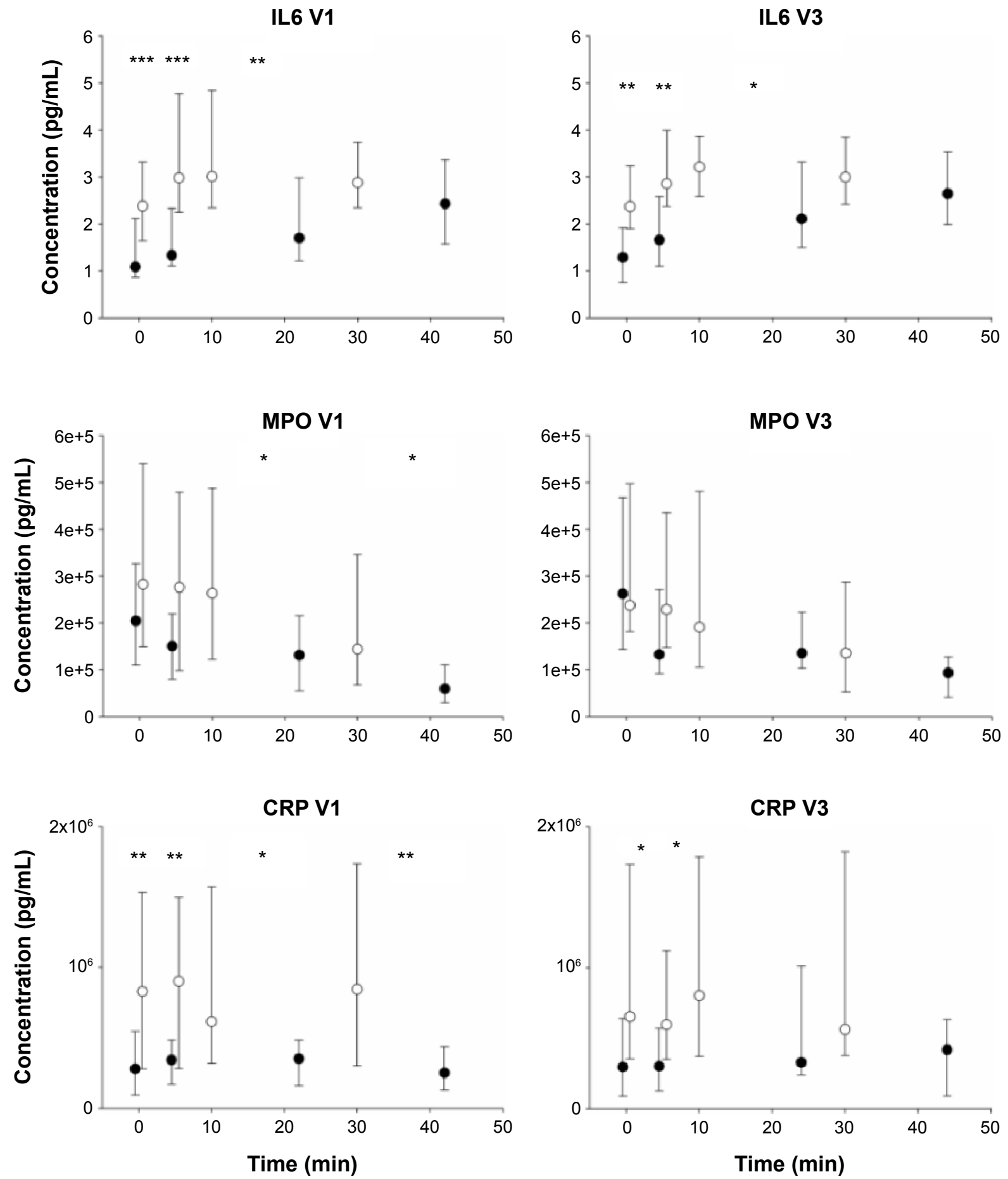

Figure 5 Time course for the peripheral blood concentrations of IL6, MPO, and CRP, separately for COPD smokers (open symbols) and healthy smokers (closed symbols). Notes: For more details, refer to the legend of Figure 4. Median levels and interquartile ranges are presented. $* * * P<0.00 \mathrm{I}, * * P<0.0 \mathrm{I}, * P<0.05$.

Abbreviations: IL6, interleukin 6; MPO, myeloperoxidase; CRP, C-reactive protein; COPD, chronic obstructive pulmonary disease; min, minute; $V$, visit.

\section{Discussion}

A constant-load exercise challenge with $75 \%$ of the maximum load was shown to increase the concentration of serum IL6, which is in line with published results..$^{24}$ In our study, this response was more pronounced in the group of healthy smokers; however, this difference might be explained by the longer duration of exercise until exhaustion. In both groups of subjects - but again more pronounced in healthy smokers - we observed a decline in the serum concentration of MPO, which has not been described before. As MPO is considered a marker for neutrophil activity, and in this respect as a biomarker for cardiovascular disease risk stratification, this observation might be related to the overall beneficial effects of physical activity. 

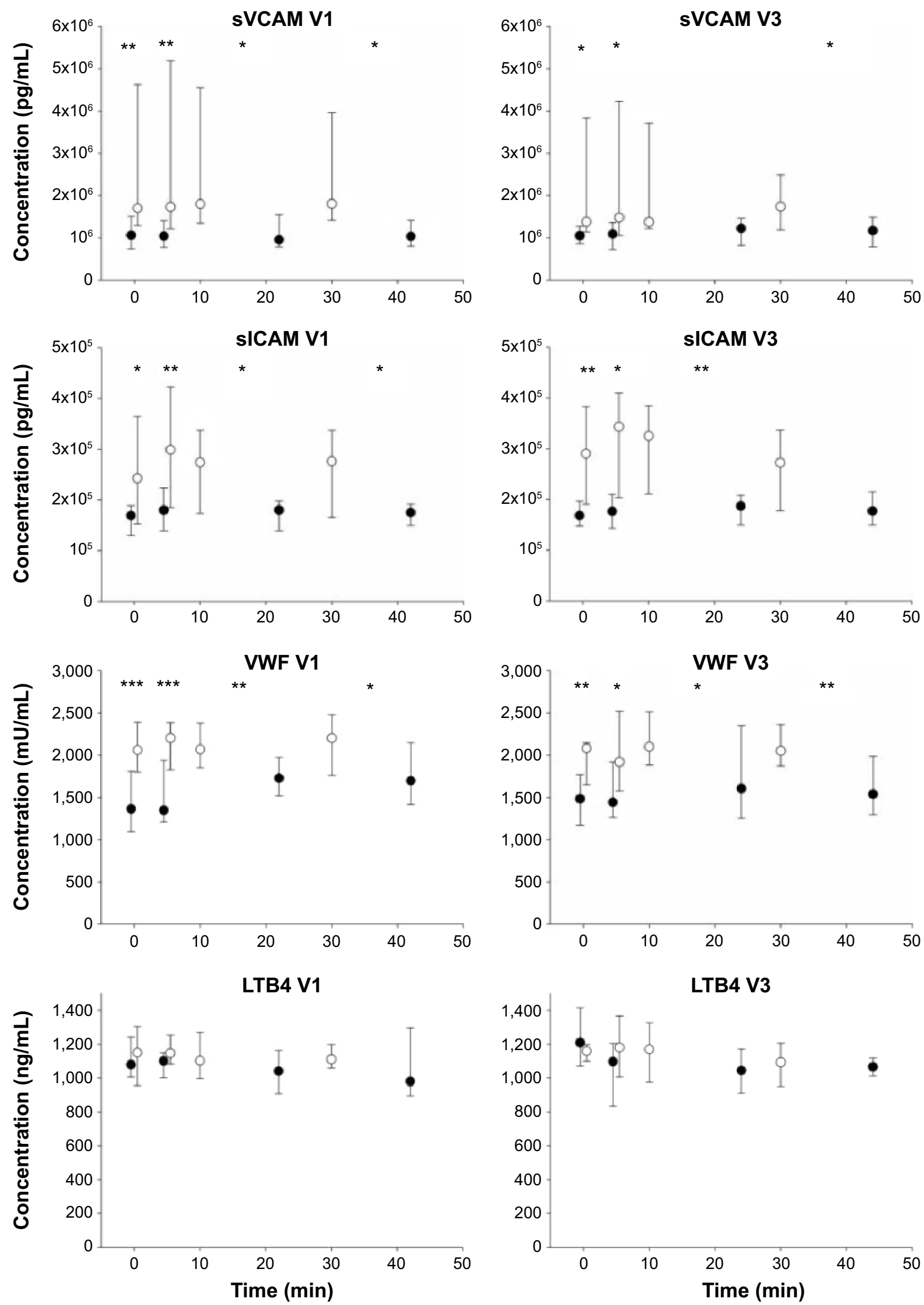

Figure 6 Time course for the peripheral blood concentrations of sVCAMI, sICAMI, VWF, and LTB4 separately for COPD smokers (open symbols) and healthy smokers (closed symbols).

Notes: For more details, refer to the legend of Figure 4. Median levels and interquartile ranges are presented. $* * * P<0.001, * * P<0.01, * P<0.05$.

Abbreviations: sVCAMI, soluble vascular cell adhesion molecule I; sICAMI, soluble intercellular adhesion molecule I; VWF, von Willebrand factor; LTB4, leukotriene B4; COPD, chronic obstructive pulmonary disease; min, minute; $\mathrm{V}$, visit. 


\section{MPO}

MPO is a widely studied molecule and plays an important role in inflammation through the formation of microbicidal reactive oxidants that are essential for the innate immune system. ${ }^{25}$ On the other hand, there is increasing evidence that MPO affects the arterial wall and endothelial function. Through lipid peroxidation, it can change the ratio of low-density and high-density lipoproteins (LDL and HDL), supporting the formation of foam cells and plaque buildup, which are processes involved in the pathogenesis of arteriosclerosis. ${ }^{26}$ In addition, MPO interacts with NO, which can attenuate NO-dependent blood vessel relaxation. ${ }^{27}$

In professional ice hockey players undergoing an incremental bicycle test until exhaustion, higher blood concentrations of MPO were shown immediately after exercise compared to baseline values. ${ }^{28}$ Under submaximal exercise, however, this effect was not observed by the same authors, both in moderately and highly trained athletes. ${ }^{29}$ These data indicate that intensive exercise potentially causing high metabolic acidosis and muscle soreness will activate neutrophils and potentially increase systemic MPO levels due to degranulation.

In our study at much lower levels of exercise, these processes apparently did not play a role. Under the constant-load exercise, MPO levels declined immediately after the start of exercise and even continued to decline during the period of 20 minutes at rest. In those subjects returning for the second challenge, the pre-exercise MPO levels were comparable again to those of the first challenge (Figure 5). Despite this, the immediate response and the continued decline during rest would suggest that a more active lifestyle could have the potential to lower the average MPO concentration. It is tempting to speculate that this effect on MPO plays a role in the clinical benefit of increasing physical activity not only in COPD patients. Data from 1820 men included in the MONICA/KORA Augsburg studies would support this by demonstrating that regular leisure-time physical activity reduces systemic MPO concentrations. ${ }^{30}$

The mechanisms involved are not known, but exercise generally leads to higher numbers of neutrophils and monocytes in peripheral blood. ${ }^{31}$ Though predominantly derived from neutrophils, both cell types are potential sources for MPO. ${ }^{32}$ It could therefore be speculated that not an increased number of neutrophils but their activation state might be a problem in COPD. ${ }^{33}$ In this respect, physical activity could have the potential to attenuate this activation state, change the MPO content, or the release phenotype of these cells.

\section{Rationale for the study design}

In an effort to amplify COPD serum biomarker signals, smokers with COPD and a sex- and age-matched group of healthy smokers underwent a constant-load exercise challenge. They were encouraged to maintain it over a period of 30 minutes, but to stop at any time earlier in case of exhaustion or symptoms. This way, each subject performed at his/her own individual level; we avoided exceeding the safe level of exercise load for COPD patients. On the other hand, we enabled a physically comparable state of exhaustion in healthy smokers by not underchallenging this group of subjects. A constant-load exercise of $75 \%$ is difficult to maintain over 30 minutes and results in mainly anaerobic energy generation in both groups. The markedly shorter exercise duration at the same percentage of $W_{\text {peak }}$ is mainly due to lower proportion of aerobic fiber type I versus fiber type II in COPD patients. ${ }^{34}$ In COPD patients, exercise capacity could be further limited due to limb muscle weakness, muscle atrophy, poorer oxidative capacity, and mitochondrial dysfunction. ${ }^{10}$ The comparable levels of lactate, however, indicate that the metabolic burden caused by the different efforts was comparable.

\section{Magnitude of the response}

The median changes between baseline and the three time points during exercise and recovery were smaller than $10 \%$ for sVCAM1, sICAM1, and LTB4. For VWF and CRP, a change exceeding $10 \%$ was observed only after rest in healthy nonsmokers. The largest changes were observed for IL6 (median $>60 \%$ from baseline) in healthy smokers and for the decline in MPO $(40 \%-60 \%)$ in both groups. Despite the fact that overall (including data of all subjects and visits) we did not find a significant change for serum CRP over time, there was a slightly $(P=0.05)$ larger increase in CRP in healthy smokers at the end of exercise when percent changes were analyzed. From this data, markers for endothelial function do not appear to be primary targets to be tested by our short-term exercise model. In addition, the limited increase in the discrimination between groups does not appear to be in favor to justify the required additional effort of this model to amplify COPD inflammatory marker signals. 


\section{Data of other studies}

In the study of Davidson et al, 20 COPD patients with lung function limitations similar to our COPD patients but all ex-smokers underwent an incremental exercise challenge until exhaustion. ${ }^{35}$ At the early time points after the end of exercise, evidence for a reduction in inflammatory cytokines was found both in serum as well as in induced sputum. This is compatible with the decline in serum MPO that we observed in our study. However, in contrast to our result and that of others, Davidson et al did not see an increase in serum IL6 between the baseline measurement and the level at the end of exercise.

In a study published by Jammes et al in $2008,{ }^{16}$ an incremental exercise protocol was used and the exercise capacity was determined using $\mathrm{VO}_{2}$ max values. Our submaximal constant-load exercise challenge did not allow the measurement of $\mathrm{VO}_{2}$ max, but we showed the differences in exercise capacity between groups by the differences in duration until exhaustion. In addition, we used healthy smokers as control group (smoking status of both COPD and control group in Ref 16 were not provided), who showed a much broader spectrum of $\mathrm{PaO}_{2}$ levels. While we found a similar difference between groups with respect to IL6 increase relative to exercise capacity, the absolute change of serum IL6 in healthy smokers was significantly larger.

Using a constant-load exercise challenge of $40 \%$ of the peak exercise level instead of $75 \%$, as in our study, Rabinovich et $\mathrm{al}^{36}$ did not find an increase in plasma IL6 during or after exercise in a group of 17 severely ill COPD patients (mean $\mathrm{FEV}_{1} \%$ predicted $40 \%$ ), indicating that a certain level of exercise is required to induce changes in systemic cytokine levels.

\section{Reproducibility of the response to challenge}

With respect to median levels, the exercise challenge model was repeatable (Figures 4-6). Looking at the respective correlation coefficients, the absolute levels of IL6 at exhaustion (TP3) were quite variable, very likely due to the rather low concentrations of IL6 in serum. For the percent changes of IL6 relative to baseline, the coefficients ranged $\sim 0.5$. A better repeatability was observed for absolute values of MPO and VWF. Importantly, the duration of exercise was highly repeatable between the two visits that took place 4 weeks apart.

\section{Conclusion}

In summary, we showed that an exercise challenge can amplify COPD biomarker signals. However, for those markers investigated, the effect was too small to justify the additional effort and to use this model in clinical practice. On the other hand, the exercise challenge was safe and well tolerated, and the systemic response was repeatable in two independent challenges; therefore this model is basically suitable for pharmacological intervention studies. One unexpected finding was the decline in serum MPO in both groups. It could be speculated that this effect is linked to the positive effects of physical activity and that a modification of the neutrophil activation state could be a potential pharmaceutical target.

\section{Acknowledgment}

We like to thank all clinical team members for their diligent support in conducting the study. The Fraunhofer Institute for Toxicology and Experimental Medicine (ITEM) is a member of the German Center for Lung Research (DZL, BREATH), Hannover, Germany. The Pulmonary Research Institute at Lung Clinic Grosshansdorf is a member of the German Center for Lung Research (DZL, ARCN), Grosshansdorf, Germany.

\section{Disclosure}

The authors report no conflicts of interest in this work.

\section{References}

1. Agustí A, Edwards LD, Rennard SI, et al; Evaluation of COPD Longitudinally to Identify Predictive Surrogate Endpoints (ECLIPSE) Investigators. Persistent systemic inflammation is associated with poor clinical outcomes in COPD: a novel phenotype. PLoS One. 2012;7:e37483.

2. Gan WQ, Man SF, Senthilselvan A, Sin DD. Association between chronic obstructive pulmonary disease and systemic inflammation: a systematic review and a meta-analysis. Thorax. 2004;59:574-580.

3. Magnussen H, Watz H. Systemic inflammation in chronic obstructive pulmonary disease and asthma: relation with comorbidities. Proc Am Thorac Soc. 2009;6:648-651.

4. Faner R, Tal-Singer R, Riley JH, et al; ECLIPSE Study Investigators Lessons from ECLIPSE: a review of COPD biomarkers. Thorax. 2014; 69:666-672.

5. Ferrari R, Tanni SE, Caram LM, Correa C, Correa CR, Godoy I Three-year follow-up of Interleukin 6 and C-reactive protein in chronic obstructive pulmonary disease. Respir Res. 2013;14:24.

6. Broekhuizen R, Wouters EF, Creutzberg EC, Schols AM. Raised CRP levels mark metabolic and functional impairment in advanced COPD Thorax. 2006;61:17-22

7. Moy ML, Teylan M, Weston NA, Gagnon DR, Danilack VA, Garshick E. Daily step count is associated with plasma C-reactive protein and IL-6 in a US cohort with COPD. Chest. 2014;145:542-550.

8. Hurst JR, Donaldson GC, Perera WR, et al. Use of plasma biomarkers at exacerbation of chronic obstructive pulmonary disease. Am J Respir Crit Care Med. 2006;174:867-874.

9. From the Global Strategy for the Diagnosis, Management and Prevention of COPD, Global Initiative for Chronic Obstructive Lung Disease (GOLD). 2010. Available from: http://www.goldcopd.com/.

10. Maltais F, Decramer M, Casaburi R, et al; ATS/ERS Ad Hoc Committee on Limb Muscle Dysfunction in COPD. An official American Thoracic Society/European Respiratory Society statement: update on limb muscle dysfunction in chronic obstructive pulmonary disease. Am J Respir Crit Care Med. 2014;189:e15-e62. 
11. O'Donnell DE, Laveneziana P. Dyspnea and activity limitation in COPD: mechanical factors. COPD. 2007;4:225-236.

12. Watz H, Waschki B, Boehme C, Claussen M, Meyer T, Magnussen H. Extrapulmonary effects of chronic obstructive pulmonary disease on physical activity: a cross-sectional study. Am J Respir Crit Care Med. 2008; 177:743-751.

13. Gagnon P, Maltais F, Bouyer L, et al. Distal leg muscle function in patients with COPD. COPD. 2013;10:235-242.

14. Steinberg JG, Ba A, Bregeon F, Delliaux S, Jammes Y. Cytokine and oxidative responses to maximal cycling exercise in sedentary subjects. Med Sci Sports Exerc. 2007;39:964-968.

15. Reihmane D, Jurka A, Tretjakovs P, Dela F. Increase in IL-6, TNFalpha, and MMP-9, but not sICAM-1, concentrations depends on exercise duration. Eur J Appl Physiol. 2013;113:851-858.

16. Jammes Y, Steinberg JG, Ba A, Delliaux S, Bregeon F. Enhanced exercise-induced plasma cytokine response and oxidative stress in COPD patients depend on blood oxygenation. Clin Physiol Funct Imaging. 2008;28:182-188.

17. Cockayne DA, Cheng DT, Waschki B, et al. Systemic biomarkers of neutrophilic inflammation, tissue injury and repair in COPD patients with differing levels of disease severity. PLoS One. 2012;7: e38629.

18. Schindhelm RK, van der Zwan LP, Teerlink T, Scheffer PG. Myeloperoxidase: a useful biomarker for cardiovascular disease risk stratification? Clin Chem. 2009;55:1462-1470.

19. Röpcke S, Holz O, Lauer G, et al. Repeatability of and relationship between potential COPD biomarkers in bronchoalveolar lavage, bronchial biopsies, serum, and induced sputum. PLoS One. 2012;7: e46207.

20. O’Donnell DE, Lam M, Webb KA. Measurement of symptoms, lung hyperinflation, and endurance during exercise in chronic obstructive pulmonary disease. Am J Respir Crit Care Med. 1998;158:1557-1565.

21. Gieger C, Geistlinger L, Altmaier E, et al. Genetics meets metabolomics: a genome-wide association study of metabolite profiles in human serum. PLoS Genet. 2008;4:e1000282.

22. Ramsay SL, Stoeggl WM, Weinberger KM, Graber A, Guggenbichler W, inventors; Biocrates Life Sciences AG, assignee. Apparatus and method for analyzing a metabolite profile. United States patent US 20070004044. 2007 Jan 4.
23. Fleiss JL. Design and Analysis of Clinical Experiments. New York: Wiley; 1986.

24. Febbraio MA, Pedersen BK. Muscle-derived interleukin-6: mechanisms for activation and possible biological roles. FASEB J. 2002;16: 1335-1347.

25. Anatoliotakis N, Deftereos S, Bouras G, et al. Myeloperoxidase: expressing inflammation and oxidative stress in cardiovascular disease. Curr Top Med Chem. 2013;13:115-138.

26. Nicholls SJ, Hazen SL. Myeloperoxidase and cardiovascular disease. Arterioscler Thromb Vasc Biol. 2005;25:1102-1111.

27. Eiserich JP, Baldus S, Brennan ML, et al. Myeloperoxidase, a leukocytederived vascular NO oxidase. Science. 2002;296:2391-2394.

28. Reihmane D, Jurka A, Tretjakovs P. The relationship between maximal exercise-induced increases in serum IL-6, MPO and MMP-9 concentrations. Scand J Immunol. 2012;76:188-192.

29. Reihmane D, Tretjakovs P, Kaupe J, Sars M, Valante R, Jurka A. Systemic pro-inflammatory molecule response to acute submaximal exercise in moderately and highly trained athletes. Environ Exp Biol. 2012;10:107-112.

30. Autenrieth CS, Emeny RT, Herder C, et al. Myeloperoxidase, but not oxidized LDL, is associated with leisure-time physical activity: results from the MONICA/KORA Augsburg Studies 1984-1995. Atherosclerosis. 2011;219:774-777.

31. Walsh NP, Gleeson M, Shephard RJ, et al. Position statement. Part one: immune function and exercise. Exerc Immunol Rev. 2011;17:6-63.

32. Klebanoff SJ. Myeloperoxidase: friend and foe. J Leukoc Biol. 2005;77:598-625.

33. Oudijk EJ, Nijhuis EH, Zwank MD, et al. Systemic inflammation in COPD visualised by gene profiling in peripheral blood neutrophils. Thorax. 2005;60:538-544.

34. Jobin J, Maltais F, Doyon JF, et al. Chronic obstructive pulmonary disease: capillarity and fiber-type characteristics of skeletal muscle. J Cardiopulm Rehabil. 1998;18:432-437.

35. Davidson WJ, Verity WS, Traves SL, Leigh R, Ford GT, Eves ND. Effect of incremental exercise on airway and systemic inflammation in patients with COPD. J Appl Physiol. 1985;2012(112):2049-2056.

36. Rabinovich RA, Figueras M, Ardite E, et al. Increased tumour necrosis factor-alpha plasma levels during moderate-intensity exercise in COPD patients. Eur Respir J. 2003;21:789-794.
International Journal of COPD

\section{Publish your work in this journal}

The International Journal of COPD is an international, peer-reviewed journal of therapeutics and pharmacology focusing on concise rapid reporting of clinical studies and reviews in COPD. Special focus is given to the pathophysiological processes underlying the disease, intervention programs, patient focused education, and self management protocols.

\section{Dovepress}

This journal is indexed on PubMed Central, MedLine and CAS. The manuscript management system is completely online and includes a very quick and fair peer-review system, which is all easy to use. Visit http://www.dovepress.com/testimonials.php to read real quotes from published authors. 